\title{
Cavitation in a Superplastic Al-Zn-Mg Alloy
}

\author{
By David A. Miller* and Terence G. Langdon**
}

\begin{abstract}
Under creep conditions, cavity growth may be controlled by vacancy diffusion or power-law creep. These two growth mechanisms are examined with reference to a superplastic $\mathrm{Al}-\mathrm{Zn}-\mathrm{Mg}$ alloy, and it is shown that the predicted dominance of power-law growth is consistent with earlier experimental observations of cavitation in this material.
\end{abstract}

(Received October 20, 1979)

\section{Introduction}

In early work on superplastic materials, it was generally considered that the formation of internal cavities was not important during deformation $^{(1)}$. More recently, it has been demonstrated that cavitation occurs during the superplastic deformation of many metals, including various $\mathrm{Cu}$ alloys ${ }^{(2)(3)}$ and the $\mathrm{Zn}$ $22 \% \mathrm{Al}$ eutectoid ${ }^{(4)(5)}$. As a result of these observations, it is now clear that the fracture of superplastic materials may be divided according to whether it arises from intrinsic plastic failure (due to necking) or cavitation failure (due to cavity interlinkage) ${ }^{(6)}$.

In a recent detailed investigation of cavitation during superplastic deformation of an $\mathrm{Al}-\mathrm{Zn}-\mathrm{Mg}$ alloy (containing $\mathrm{Al}-9.7 \mathrm{wt} \% \mathrm{Zn}-$ $0.85 \mathrm{wt} \% \mathrm{Mg}-0.30 \mathrm{wt} \% \mathrm{Zr}$ ), Matsuki et al. ${ }^{(7)}$ reported very extensive cavitation in specimens tested at temperatures from 733 to $793 \mathrm{~K}$. In particular, the microstructures of longitudinal sections of specimens tested at 733 and $793 \mathrm{~K}$ (their Photos. 3 and 4, respectively) showed large cavities which were considerably elongated in the direction of the tensile stress. The purpose of this communication is to examine the process of cavity growth in this alloy, and to compare the theoretical predictions with the experimental observations.

* Department of Mechanical Engineering, University of Bristol, Bristol BS8 1TR, England.

** Department of Materials Science, University of Southern California, Los Angeles, California 90007, U.S.A.

\section{Mechanisms of Cavity Growth}

There are two major mechanisms for cavity growth under creep conditions. First, a cavity may grow by accepting vacancies from an adjacent zone in the grain boundary plane. Second, growth may be controlled by powerlaw creep in the material outside of this zone. In practice, there is a transition from predominantly diffusion growth at small strains and low stress levels to predominantly powerlaw growth at large strains and high stress levels.

The appearance of the cavities is different for these two growth processes. Diffusion growth leads to essentially spherical cavities preferentially located on grain boundaries lying approximately perpendicular to the stress axis, whereas power-law growth leads to cavities which are elongated in the direction of the tensile stress. Both types of cavities have been observed in a superplastic $\mathrm{Cu}$ alloy ${ }^{(3)}$.

It has been demonstrated ${ }^{(8)}$ that there is good agreement between the theories of cavity growth and experimental observations of cavitation in a microduplex alloy steel $(\mathrm{Fe}-4 \mathrm{wt} \% \mathrm{Ni}-3 \mathrm{wt} \%$ Mo-1.6 wt $\%$ Ti-0.03 wt $\% \mathrm{C})^{(9)}$, a commercial $\mathrm{Cu}$ alloy $(\mathrm{Cu}-2.8 \mathrm{wt} \% \mathrm{Al}-1.8 \mathrm{wt} \% \mathrm{Si}-0.4 \mathrm{wt} \%$ Co) ${ }^{(3)}$, and $\mathrm{Zn}-22 \% \mathrm{Al}^{(4)}$. In the investigation of Matsuki et al. ${ }^{(7)}$, the experimental observation of cavities elongated along the tensile axis is consistent with growth controlled by powerlaw creep. To check whether this is in agreement with the theories of cavity growth, it is necessary to examine the two growth processes independently.

For diffusion growth, the rate of change of

1980 Vol. 21 
cavity radius, $r$, with strain, $\varepsilon$, is given by ${ }^{(10)}$

$$
\left[\frac{d r}{d \varepsilon}\right]_{d}=\frac{1}{\dot{\varepsilon}}\left[\frac{\Omega \delta D_{\mathrm{gb}}(\sigma-2 \gamma / r)}{2 k \operatorname{Tr}^{2}[\ln (a / 2 r)-1 / 2]}\right]
$$

where $\dot{\varepsilon}$ is the strain rate, $\Omega$ is the atomic volume, $\delta$ is the width of the grain boundary ( $\simeq 2 b$ where $b$ is the Burgers vector), $D_{\mathrm{gb}}$ is the coefficient for grain boundary diffusion, $\sigma$ is the applied stress, $\gamma$ is the surface energy, $k$ is Boltzmann's constant, $T$ is the absolute temperature, and $a$ is the cavity spacing. The denominator of eq. (1) may be simplified by putting $[\ln (a / 2 r)-1 / 2]=1$. Similar relationships are also available from several different analyses $^{(11) \sim(13)}$.

For power-law growth, the equivalent expression is ${ }^{(14)}$

$$
\left[\frac{d r}{d \varepsilon}\right]_{p}=r-\left[\frac{3 \gamma}{2 \sigma}\right] .
$$

Again, several similar relationships are also available ${ }^{(15) \sim(17)}$.

It follows from eqs. (1) and (2) that the dominant process may be determined by logarithmically plotting $d r / d \varepsilon$ versus $r$.

\section{Analysis of Data}

\section{for Superplastic $\mathbf{A l}-\mathbf{Z n}-\mathbf{M g}$}

Calculations were performed for the $\mathrm{Al}-\mathrm{Zn}$ $\mathrm{Mg}$ alloy by putting $\Omega=1.66 \times 10^{-29} \mathrm{~m}^{3(18)}$, $\delta=2 b=5.72 \times 10^{-10} \mathrm{~m}, \quad D_{\mathrm{gb}}=1.86 \times 10^{-4} \mathrm{exp}$ $(-86000 / R T) \mathrm{m}^{2} \mathrm{~s}^{-1}$ where $R$ is the gas constant $\left(8.31 \mathrm{~J} \mathrm{~mol}^{-1} \mathrm{~K}^{-1}\right)^{(19)}$, and $\gamma=1.1 \mathrm{~J}$ $\mathrm{m}^{-2(20)}$.

Two examples are shown in Figs. 1 and 2. Figure 1 is for a temperature of $733 \mathrm{~K}$, a strain rate of $1.3 \times 10^{-2} \mathrm{~min}^{-1}\left(2.2 \times 10^{-4} \mathrm{~s}^{-1}\right)$, and a flow stress of $\sigma=2.0 \mathrm{MPa}$. Figure 2 is for a temperature of $793 \mathrm{~K}$, a strain rate of $1.3 \times$ $10^{-2} \mathrm{~min}^{-1}$, and a flow stress of $\sigma=6.0 \mathrm{MPa}$. These two conditions correspond to Photos. 3 and 4 , respectively, in the report by Matsuki et $a l .^{(7)}$ In each case, the solid line represents $(d r / d \varepsilon)_{d}$ in eq. (1) for diffusion growth and the broken line shows $(d r / d \varepsilon)_{p}$ in eq. (2) for powerlaw growth.

The two sets of curves in Figs. 1 and 2 show that $(d r / d \varepsilon)_{p}>(d r / d \varepsilon)_{d}$ at all values of $r$ for these experimental conditions in the $\mathrm{Al}-\mathrm{Zn}-\mathrm{Mg}$

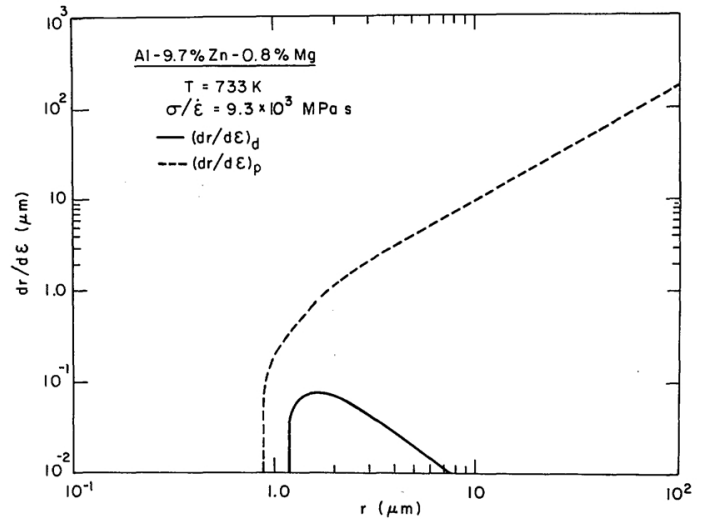

Fig. 1 Cavity growth rate vs cavity radius for a superplastic $\mathrm{Al}-\mathrm{Zn}-\mathrm{Mg}$ alloy at $733 \mathrm{~K}, \sigma=2.0 \mathrm{MPa}$, $\dot{\varepsilon}=2.2 \times 10^{-4} \mathrm{~s}^{-1}$, and $\sigma / \dot{\varepsilon}=9.3 \times 10^{3} \mathrm{MPa} \mathrm{s}$.

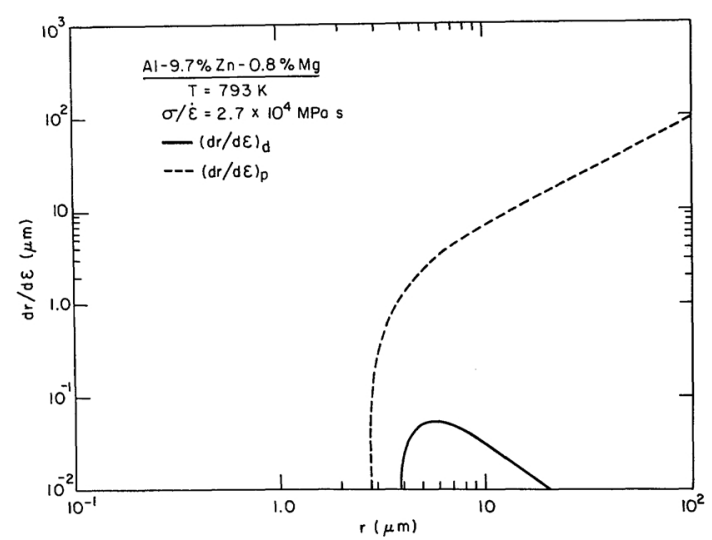

Fig. 2 Cavity growth rate vs cavity radius for a superplastic $\mathrm{Al}-\mathrm{Zn}-\mathrm{Mg}$ alloy at $793 \mathrm{~K}, \sigma=6.0 \mathrm{MPa}$, $\dot{\varepsilon}=1.3 \times 10^{-2} \mathrm{~s}^{-1}$, and $\sigma / \dot{\varepsilon}=2.7 \times 10^{4} \mathrm{MPa} \mathrm{s}$.

alloy. Thus, the calculations indicate that power-law growth of the cavities is dominant over the entire range of stable radii for the conditions investigated by Matsuki et al. ${ }^{(7)}$, and this confirms the experimental observations of cavities which are elongated in the direction of the tensile stress.

The present calculations for an $\mathrm{Al}-\mathrm{Zn}-\mathrm{Mg}$ alloy are similar to the results reported earlier for the $\mathrm{Zn}-22 \% \mathrm{Al}$ eutectoid ${ }^{(8)}$. It is therefore suggested that diffusion growth, through eq. (1), is only important in the $\mathrm{Al}-9.7 \% \mathrm{Zn}-0.8 \% \mathrm{Mg}$ alloy at very low strain rates. 


\section{Summary and Conclusions}

(1) There are two different mechanisms of cavity growth and these predict different relationships for $d r / d \varepsilon$, where $r$ is the cavity radius and $\varepsilon$ is the strain.

(2) Calculations for a superplastic $\mathrm{Al}-\mathrm{Zn}$ $\mathrm{Mg}$ alloy show that power-law growth is more important than diffusion growth under two different experimental conditions.

(3) The predictions are consistent with earlier experimental observations of cavitation in this alloy.

\section{Acknowledgment}

This work was supported by the United States Department of Energy under Contract DEAS03-76SF00113 PA-DE-AT03-76ER10408.

\section{REFERENCES}

(1) R. H. Johnson: Met. Rev., 15 (1970), 115.

(2) S. Sagat and D. M. R. Taplin: Acta Met., 24 (1976), 307.

(3) S. -A. Shei and T. G. Langdon: J. Mater. Sci., 13 (1978), 1084.

(4) H. Ishikawa, D. G. Bhat, F. A. Mohamed and T. G. Langdon: Met. Trans. A, 8A (1977), 523.
(5) D. A. Miller and T. G. Langdon: Met. Trans. A, 9A (1978), 1688.

(6) D. M. R. Taplin, G. L. Dunlop and T. G. Langdon: Ann. Rev. Mater. Sci., 9 (1979), 151.

(7) K. Matsuki, Y. Ueno, M. Yamada and Y. Murakami: J. Japan Inst. Metals, 41 (1977), 1136.

(8) D. A. Miller and T. G. Langdon: Met. Trans. A, 10A (1979), 1869.

(9) C. W. Humphries and N. Ridley: J. Mater. Sci., 9 (1974), 1429.

(10) M. V. Speight and J. E. Harris: Metal Sci. J., 1 (1967), 83.

(11) M. V. Speight and W. Beeré: Metal Sci., 9 (1975), 190.

(12) R. Raj and M. F. Ashby: Acta Met., 23 (1975), 653.

(13) R. Raj, H. M. Shih and H. H. Johnson: Scripta Met., 11 (1977), 839.

(14) J. W. Hancock: Metal Sci., 10 (1976), 319.

(15) W. Beeré and M. V. Speight: Metal Sci., 12 (1978), 172.

(16) R. J. DiMelfi and W. D. Nix: Intl. J. Fracture, 13 (1977), 341.

(17) W. D. Nix, D. K. Matlock and R. J. DiMelfi: Acta Met., 25 (1977), 495.

(18) M. F. Ashby: Acta Met., 20 (1972), 887.

(19) F. A. Mohamed and T. G. Langdon: Met. Trans., 5 (1974), 2339.

(20) H. Jones: Metal Sci. J., 5 (1971), 15. 